\title{
Exergy Analysis Of Cross Flow Shell and Tube Condenser
}

\author{
*Barot Umeshkumar Bhupendrabhai*
}

\begin{abstract}
:-
Heat exchangers are of considerable importance, and widely used in various types of applications, therefore the design of heat exchangers continues to be a centrally important issue in energy conservation. To determine the optimal design and operational conditions of heat exchangers, the performance of heat exchangers should be evaluated correctly, thus the usage of accurate and reliable performance evaluation methods is the key to the successful design and optimal use of heat exchangers. Reviews includes Energy and Exergy analysis of thermal Power Plant system based on advance thermodynamic topics Exergy analysis which is the combination of first law and second law of Thermodynamics and highlights inefficiencies of a system. In entire reviews the need for the systematic design of heat exchangers using a second law-based procedure is recalled and discussed, and then, second-law based performance evaluation criteria for heat exchangers are presented. These criteria have been grouped into two classes: the criteria that use entropy as evaluation parameter and the criteria that use exergy as evaluation parameter. They present the entropy as an evaluation parameter in the following forms Entropy generation rate; Entropy generation number; Augmentation entropy generation number; Heat exchange reversibility norm (HERN); Local entropy generation number, and also use of exergy as evaluation parameter in the forms of various analysis of operating conditions of the systems.
\end{abstract}

\section{INTRODUCTION:-}

Energy consumption is one of the most important indicator showing the development stages of countries and living standards of communities. Population increment, urbanization, industrializing, and technologic development result directly in increasing energy consumption. This rapid growing trend brings about the crucial environmental problems such as contamination and greenhouse effect. Currently, $80 \%$ of electricity in the world is approximately produced from fossil fuels (coal, petroleum, fuel-oil, natural gas) fired thermal power plants, whereas $20 \%$ of the electricity is compensated from different sources such as hydraulic, nuclear, wind, solar, geothermal and biogas. Usually, the performance of thermal power station is evaluated through energetic performance criteria based on first law of thermodynamics, including electrical power and thermal efficiency. Coal requirement grew by $3 \%$ in 2013; below the 10-year of average $3.9 \%$ but it's still the fastest-growing fossil fuel. Coal's share of universal primary energy need reached $30.1 \%$, the highest since 1970. Consumption outer to the OECD rose by a below-average $3.7 \%$, but still noticed for $89 \%$ of global growth. As notice earlier China was the least absolute growth since 2008 but the country still accounted for $67 \%$ of global growth. As per the record India is second largest volumetric increase and deposited for $21 \%$ of global growth. Requirement of OECD raised by $1.4 \%$, higher in the Japan and United States offsetting declines in the EU. Global coal production increased by $0.8 \%$, the least growth since 2002. Indonesia (+9.4\%) and Australia (+7.3\%) offset a decline in the US $(-3.1 \%)$, its noticed that
China $(+1.2 \%)$ is the weakest volumetric growth in production since 2000 .

\section{OVERVIEW OF POWER PLANT:-}

In Gujarat, India, Wanakbori thermal power station is one of the coal fired power station. It is located in Kheda district. There are seven units and each unit has 210MW capacity. Wanakbori Thermal Power Station (WTPS) is ISO 9000:2008 and 14001:2004 confirmed plants started in 1982 as a super thermal power station of Gujarat. It gets coal from coalmines arranges at Orissa, Madhyapradesh, West Bengal, Andhra Pradesh and Korea Reva mines. For primary requirements of water in whole power station are satisfied with Mahi River and Narmada canal. One demineralizing plant is under operation to deposits up flawless make-up water in power plant. All units were built by Bharat Heavy Electrical Ltd. GSECL's future development unit no. 8 which will be focused around super critical boiler of limit $800 \mathrm{MW}$ suggested at Wanakbori thermal power plant. 

ISSN : 2248-9622, Vol. 7, Issue 7, ( Part -1) July 2017, pp.83-85

\section{Installed Capacity Of Thermal Power Pant At Wanakbori :-}

\begin{tabular}{|c|c|c|c|}
\hline Unit & $\begin{array}{c}\text { Installed } \\
\text { Capacity } \\
\text { (MW) }\end{array}$ & $\begin{array}{c}\text { Date of } \\
\text { Commissioning }\end{array}$ & Status \\
\hline 1 & 210 & March,1982 & Working \\
\hline 2 & 210 & January, 1983 & Working \\
\hline 3 & 210 & March, 1984 & Working \\
\hline 4 & 210 & March, 1986 & Working \\
\hline 5 & 210 & September, 1986 & Working \\
\hline 6 & 210 & November, 1987 & Working \\
\hline 7 & 210 & December, 1998 & Working \\
\hline
\end{tabular}

SHELL AND TUBE CONDENSER:-

In shell and tube condensers, the condensation may occur inside or outside the tubes. The orientation of the unit may be vertical or horizontal.

\section{HORIZONTALSHELLSIDECONDENSERS :-}

The shell and tube condensers for process plants are covered by the Tubular Exchanger Manufacturers Association (TEMA). Shows various TEMA shell types. All shell types are used as condensers except the K-shell. The K-shell is a kettle reboiler. A very important feature of a condenser as compared with any othertype of heat exchanger is that it must have a vent for removal of noncondensable gas.

Thus, an E type condenser will have two outlet nozzles, one for the vent and other for the condensate outlet. Therefore, it is clear that there is no chance of non-condensable accumulation during condenser operation. Hence vent is provided. The Eshell is the most common due to its cheapness and simplicity. In this shell, the shell fluid enters at one end of the shell and leaves at the other end; that is, there is one pass on the shell side. The tubes may have a single or multiple passes and are supported by transverse baffles.

\section{FIRST LAW AND SECOND LAW EFFICIENCY:-}

Acommon measure on energy use efficiency is the first law efficiency, $\eta \mathrm{I}$. The ratio of the output energy of a device to the input energy of the device is known as the first law efficiency. The quantities of energy is parameter which concerned with first law of thermodynamics, and disregards the forms in which the energy exists .It does not also distinguish between the energies available at different temperatures. It is the second law of thermodynamics which provides a means of assigning a quality index to energy.The concept of available energy or exergy provides a useful measure of energy quality, with this concept it is possible to analyze means of minimizing the consumption of available energy to perform a given process, thereby ensuring the most efficient possible conversion of energy for the required task. The second law efficiency, $\eta I I$ of a process is illustrated as the ratio of the minimum available energy (or exergy) which must be consumed to do a task divided by the actual amount of available energy (or exergy) consumed is performing the task.

$\eta \mathrm{II}=$ Minimum exergy intake to perform work /Actual exergy intake to perform same work.

Alirezafalahat, Sadeghvosough

,Hasannasresfehani,Azambehjat and Royanaseri rad, The primary details of this paper are to examine the system components evenly and to identify and quantify the sites having higher energy and exergy losses at cycle. Furthermore, the effect of varying the condenser pressure on this analysis will also be presented. The performance of the plant was calculatedby a part-wise modeling and an allinclusive break-up of exergy and energy losses for the considered plant has been presented. In this study they conclude, an energy and exergy analysis as well as the effect of varying the condenser pressure on the subcritical model power station has been presented. The analyses show that the condenser pressure is an important parameter that affects the output power, power potential and thermal and exergy efficiency of the cycle. Considering the essential limitation of this parameter as well as the turbine limitation, the minimum granted pressure of condenser should be chosen to develop output power and maximum efficiency.

Ajeet Singh Sikarwar, DevendraDandotiya, Surendra Kumar Agrawal, Ajeet Singh Sikarwar, DevendraDandotiya, Surendra Kumar Agrawal, in this paper evaluated all the aspects of condenser which affecting the performance of power plant. Thermal power stations are designed based on needed conditions (like a good quality of steam, temperature and pressure of steam etc.), but practically inlet conditions are not as per the designed conditions. In practical circumstances, when power plants are installed there are lots of restrictions. This tends to decrease orincrease heat rate and output power of thermal power plants. Because of these conditions, the designed power and heat rate are never gained. Changing in the power outputs from plant are always a matter of disputation. So the power and heat rate's parameter are generated for different conditions of condenser pressure, flow rate of water through the condenser and temperature difference.

VikramHaldkar $\dot{A}$, Abhay Kumar Sharma $\dot{A}$, R.K.Ranjan $\dot{A}$ and V.K.Bajpai $\dot{B}$ in IJTT. On the basis 
of site measurement and design data collection performance of the Condenser unit can be examined according to the author. These evaluations show that if operating conditions change, then power output and heat rate also change. This paper relates with the factors or parameters which decreased the efficiency of the condenser and power station.

In this paper, reasons which effecting the condenser performance are digression due to cooling water inlet temperature, digression due to water flow rate and deviation due to condenser pressure in energy efficiency of plant is consider.

\section{OBJECTIVE OF PROJECT WORK:-}

There are many investigations carried out to improve the design of shell and tube heat condenser. But most of the researches are related to the optimization of the geometrical dimensions of the heat exchanger. It is seen that only few papers are available on analysis and optimization of operating condition of the heat exchanger and particularly condenser. The present study focuses on the analysis of operating conditions of cross flow shell and tube condenser. Minimization of the exergy destruction is considered as objective of analysis which is subjected to condensation of entire mass flow rate of steam.

\section{PROBLEM IDENTIFICATION:-}

The Exergy efficiency and exergy destruction is to formulate for various operating conditions of shell and tube condenser. First of all, formulation and model to analyses the given system is defined mathematically. In the next section, calculation procedure is discussed to find out values of given different operating conditions. The present chapter contains the results of exergy analysis in terms of exergy efficiency and exergy destruction under different operating condition of the Shell and tube type condenser of WTPS.

\section{CONCLUSION:-}

Exergy analysis in terms of exergy destruction and exergy efficiency of 6 units of condenser of power plant concludes that exergy efficiency of all condensers are lesser then design value of $60 \%$. Performance of unit no. 1 and 4 condensers are work satisfactory because their exergy efficiency are nearer to design efficiency, while condenser unit 2, 3, 5 and 6 are not working efficiently. Reasons for lower exergy efficiency are cooling water temperature difference than design value. Mass flow rate through condenser directly effects on exergy efficiency. Higher inlet cooling water temperature in condenser leads to lower exergy efficiency. From the result of exergy efficiency of six units of power plant it is also conclude that condenser of unit no. 2 has a lower exergy efficiency and higher exergy destruction compare to other units of power plant and its about 0.2469 exergy efficiency and $14694 \mathrm{~kW}$. Effect of variation of cooling water temperatures on exergy analysis of condenser conclude that with decrease of condenser cooling water temperature from 31.20 to 28.84 at 27 ambient temperature, exergy destruction also decrease from $14694 \mathrm{~kW}$ to $14193 \mathrm{~kW}$. So it is better to operate the condenser at as low as possible cooling water temperature.

\section{RESEARCH PAPER}

[1] Saidur.R, Sattar, M.A., Masjuki, H.H., Ahmed, "An estimation of the energy and exergy efficiencies for the energy resources" use in the transportation sector in Malaysia. Energy Policy (2007), 35(8), pp.4018-4026.

[2] Rosen, M.A., Dincer I. "Exergy as the confluence of energy, environment and sustainable development". Exergy, an International Journal (2001), 1(1), 3-13.

[3] Amir vosough, Alirezafalahat, Sadeghvosough, Hasannasresfehani, Azambehjat And Royanaserirad, "Improvement Power Plant Efficiency with Condenser Pressure", International Journal Of Multidisciplinary Sciences And Engineering ( June-2011),ISSN: 2045-7057, Vol. 2, No.3,pp.38-43.

[4] Ajeet Singh Sikarwar, DevendraDandotiya, Surendra Kumar Agrawa,Ajeet Singh Sikarwar, DevendraDandotiya, Surendra Kumar Agrawal,"Performance Analysis of Surface Condenser under Various Operating Parameters",International Journal of Engineering Research and Applications( JulAug 2013), ISSN: 2248-9622, Vol. 3,Issue 4,pp.416-421. 